\title{
Retrieval processes in arithmetic production and verification
}

\author{
JAMIE I. D. CAMPBELL and DEREK P. M. TARLING \\ University of Saskatchewan, Saskatoon, Saskatchewan, Canada
}

\begin{abstract}
To investigate whether arithmetic production and verification involve the same retrieval processes, we alternated multiplication production trials (e.g., $9 \times 6=$ ?) with verification trials $(4 \times 9=36$, true or false?) and analyzed positive error priming. Positive error priming is the phenomenon in which errors frequently match correct answers from preceding problems. Production errors were strongly primed by previous production trials (the error-answer matching rate was about $90 \%$ greater than expected by chance), but production errors were not strongly primed by previous verification trials $(\approx 13 \%$ above chance). Conversely, false-verification errors were primed by previous verification trials $(\approx 25 \%$ above chance), but not by production trials. The results indicated that arithmetic production and verification were mediated by different memory processes and suggest a familiaritybased over a retrieval-based model of arithmetic verification.
\end{abstract}

The empirical investigation of cognitive arithmetic has relied primarily on two experimental procedures. In the verification procedure, an arithmetic equation is presented (e.g., $4 \times 8=24$ ), and subjects evaluate as quickly as possible whether the equation is true or false. In the production task, a problem is presented (e.g., $4 \times 8$ ) and subjects state the correct answer as quickly as possible. A basic issue regarding these procedures is the extent to which they measure the same memory processes. One view is that both tasks involve a common computational process, which usually is assumed to be answer retrieval for skilled individuals (e.g., Ashcraft, 1982, 1992; Ashcraft, Fierman, \& Bartolotta, 1984). In the case of production, the answer is retrieved and stated, whereas in the case of verification, the answer is retrieved and compared to the presented answer. Alternatively, the two tasks may be mediated by different processes. Whereas production usually involves answer retrieval, verification may be based on the plausibility (Krueger, 1986) or familiarity of the whole equation (Zbrodoff \& Logan, 1990 ) and not require retrieval of the correct answer.

Understanding arithmetic verification is important because the task has been used widely in both theoretical (e.g., Ashcraft, Yamashita, \& Aram, 1992; Dagenbach \& McCloskey, 1992; Gonzalez \& Kolers, 1982; Noël \& Seron, 1992) and applied contexts (e.g., Geary, Widaman, Little, \& Cormier, 1987; Rogers \& Fisk, 1991). For example, the verification procedure is commonly used in experimental analyses of the development of arithmetic

We thank M. Ashcraft, J. A. Lefevre, M. Masson, P. Meagher, and J. Zbrodoff for very helpful comments on a previous draft. This research was supported by Grant OPG0001980 from the Natural Sciences and Engineering Research Council of Canada. Correspondence should be addressed to J. I. D. Campbell, Department of Psychology, University of Saskatchewan, Saskatoon, SK, Canada S7N 5A5 (email: campbell@sask.usask.ca). skill (Ashcraft, 1982; Koshmider \& Ashcraft, 1991; Lemaire, Barrett, \& Fayol, 1994; Lemaire \& Fayol, 1995), although, in everyday practice, arithmetic production is probably much more common than arithmetic verification. Furthermore, it is common for researchers to presuppose a specific model of verification. For example, the validity of the retrieve-compare model was assumed in several recent componential analyses of both simple and complex arithmetic (Frensch \& Geary, 1993; Geary, Widaman, \& Little, 1986; Widaman \& Little, 1992). Similarly, in analyses of arithmetic deficits due to brain injury, arithmetic verification has been used as a control condition to assess the integrity of retrieval processes assumed to operate in arithmetic production (e.g., McCloskey, Sokol, \& Goodman, 1986). This is appropriate only if arithmetic production and verification involve essentially identical computational processes.

We begin with a review of retrieval-based and familiaritybased approaches to arithmetic verification. We then describe error priming in arithmetic production and explain how error priming may be used to discriminate retrievalbased from familiarity-based verification.

\section{Retrieve-Compare Model of Verification}

Four stages are hypothesized in the retrieve-compare model of arithmetic verification introduced by Ashcraft and Battaglia (1978; see also Ashcraft, 1982, 1987, 1992): (1) encode the problem and presented answer, (2) compute the answer to the problem, (3) decide if the computed and presented answers are the same or different, (4) execute the "true" or "false" response. It is assumed in the model that computation by adults and older children usually involves answer retrieval and that retrieval is mediated by automatic spreading activation through a network of related problems and answers. For example, the problem $2 \times 7$ activates the memorized multiples of 2 and 7 , and answers that are numerically near to the cor- 
rect answer are more strongly activated. The correct answer is identified by the intersection of activation from both operands. In Ashcraft's model, speed of retrieval is determined by the associative strength linking the problem and its correct answer, and strength is assumed to depend primarily on problem frequency. In general, problem frequency decreases with problem size (Hamann \& Ashcraft, 1986). Also, consistent with the relations among frequency, strength, and response time (RT) hypothesized in the model, it is commonly observed that RT tends to increase with problem size (see Ashcraft, 1992; Campbell \& Oliphant, 1992; Gallistel \& Gelman, 1992; LeFevre, Sadesky, \& Bisanz, in press; Siegler, 1988). Furthermore, in keeping with the assumption that verification and production involve the same retrieval process, Ashcraft, Fierman, and Bartolotta (1984) tested first graders, fifth graders, and college students on verification and production of simple addition facts and found no task $\times$ problem size interactions beyond the first grade.

Interactions between the retrieval and comparison stages in Ashcraft's model account for relatedness effects observed in verification of false-answer equations: RTs to false equations are longer when the split (i.e., numerical difference) between the presented and correct answer is small (e.g., $4+8=13$ ) compared to larger splits $(4+8=17)$ (Ashcraft \& Stazyk, 1981; Stazyk, Ashcraft, \& Hamann, 1982). Similarly, RTs to false equations are longer and errors are more common when the incorrect answer is arithmetically related to the problem. For example, RT is relatively slow when a presented answer is the correct answer to another problem in the same times table (e.g., $4 \times 7=24$ ) (Campbell, 1987; Stazyk et al., 1982) or the correct answer for a different arithmetic operation (e.g., $4 \times 7=11$ ) (Winkelman \& Schmidt, 1974; Zbrodoff \& Logan, 1986). It is assumed in Ashcraft's model that the verification decision is based on a comparison of the activation levels of the computed and presented answers in the retrieval network (see, e.g., Ashcraft, 1992, p. 88). Because problems produce strong activation of numerically near and related answers, the activation levels of these answers may be relatively close to the activation level of the correct answer compared to the weak activation of numerically distant or unrelated answers. Given that the same-different decision is more difficult when activation levels are similar, it follows that the comparison stage should require longer RTs and be more error prone when a presented false answer is near or related to the correct answer.

The retrieve-compare model is plausible and provides straightforward explanations for the major phenomena of verification, but it is likely that use of a retrieve-compare strategy depends on a number of factors. For example, Ashcraft and Stazyk (1981) found that whereas falseverification RTs are generally longer than true RTs, splits of \pm 13 in addition verification resulted in shorter RTs than did true equations. This suggests that if the split is large enough, subjects quickly recognize that the equation is implausible without necessarily retrieving the answer to the problem. Krueger (1986; Krueger \& Hallford, 1984) similarly proposed that subjects can make plausibility judgments in verification on the basis of numerical relationships (e.g., a product is odd only if both operands are odd), thereby bypassing retrieval of the correct answer (see also Lemaire \& Fayol, 1995). Thus, when there are salient characteristics of false equations that reliably distinguish them from true equations, subjects may make their verification decisions on the basis of the plausibility of the equation. Strategy choice will also be sensitive to the overall speed-accuracy criterion subjects adopt. Given that plausibility or familiarity information can be available faster than a specific answer (Reder \& Ritter, 1992), strategies based on a global assessment of the equation would be most likely when experimental instructions emphasize speed rather than accuracy.

However, even under conditions where a retrievecompare strategy is plausible, there are reasons to doubt that computation in verification and production is equivalent. Campbell (1987) found that differences in problem difficulty observed on "true" multiplication equations were attenuated relative to production trials. This suggests that computational processes can differ in the two tasks, perhaps because the presented answer in verification acts as a priming stimulus (see also Campbell, 1991; Meagher \& Campbell, 1995). Consistent with the possibility that production and verification involve different computational processes, Dagenbach and McCloskey (1992) demonstrated that production and verification performance can be differentially affected by brain injury. Dagenbach and McCloskey tested an elderly man with left-hemisphere damage, R.G., on subtraction, addition, and multiplication using both verification and production tasks. In the production task, R.G. was much less error prone for subtraction than for addition or multiplication. In the verification task, however, R.G.'s error rate did not vary among the operations. Thus a variety of phenomena suggest that production and verification performance may depend on different types of memory processes or strategies (see also Miller, Perlmutter, \& Keating, 1984).

\section{Resonance Model of Verification}

Zbrodoff and Logan (1990) directly tested the retrievecompare model and developed an alternative account that emphasizes the role of familiarity or memory resonance in arithmetic verification. They argued that if a two-stage production-plus-comparison (i.e., retrievecompare) strategy is the dominant strategy for arithmetic verification, it should be possible to affect the time course of each stage independently. Specifically, once the retrieval stage is completed, RT effects must be associated with the comparison stage, and factors that affect the retrieval stage (e.g., problem size) should have no effect. Similarly, manipulating split (i.e., the difference between the true answer and the presented answer) 
should affect only the comparison stage, and thus split should not interact with retrieval variables (e.g., problem size or difficulty).

Zbrodoff and Logan (1990) tested adult subjects on verification of simple addition (Experiment 1 ) and multiplication problems (Experiment 2) with splits of 0 (i.e., the correct answer), +2 , and +12 . The delay between presentation of the problem operands (e.g., $4 \times 8$ ) and presentation of the verification answer (e.g., 34) was manipulated from 0 to $1,000 \mathrm{msec}$ in $250-\mathrm{msec}$ steps. RTs were measured from presentation of the verification answer. The 1,000-msec delay was intended to provide sufficient time for subjects to compute or retrieve the true answer before the answer to be verified appeared, which, under the retrieve-compare model, should eliminate the problem-size effect. Control subjects were tested in a number comparison task in which a sum or product was directly compared to a comparison number that appeared after the same 0 - to 1,000 -msec delays. The purpose of the control condition was to mimic the putative comparison stage hypothesized in the retrieve-compare model. Zbrodoff and Logan reasoned that if split effects are due to a comparison process, equivalent split effects would be observed in both the verification and comparison tasks.

In apparent contradiction to the retrieve-compare model, Zbrodoff and Logan (1990) found that although the problem-size effect was reduced as delay increased, it was still present even with the 1,000 -msec delay between the problem and verification answer. Furthermore, split effects were larger in the arithmetic task than in the number comparison task. Similar results were obtained in Experiment 3 (addition) and Experiment 4 (multiplication), in which subjects pressed a button when they were "ready" for the verification answer. However, in Experiment 5 (addition) and Experiment 6 (multiplication), in which subjects generated an answer before getting the answer to be verified, there was no evidence of a problem-size effect (i.e., in the response to the verification answer) statistically different from that observed in the number comparison task.

Zbrodoff and Logan (1990) concluded that these results were inconsistent with the retrieve-compare model of verification. As an alternative, they proposed that activation in the memory network representing arithmetic facts can be interpreted by two different types of macroprocesses, one that mediates arithmetic production and another that mediates verification. For the production task, there is a macroprocess that analyzes the relative activation of individual memory nodes in the network and selects the most strongly activated node for retrieval. For verification, a different macroprocess assesses the overall activation or resonance within the network, which provides an index of the familiarity or novelty of the stimulus (see Metcalfe, 1993). For verification, therefore, no answer-retrieval stage is involved. The resonance model of arithmetic verification is similar to models of recognition memory in which recognition is based on the global response of the memory system to a stimulus (see, e.g., Gillund \& Shiffrin, 1984; Humphreys, Bain, \& Pike, 1989). When an equation is presented, resonance accrues continuously and subjects make a "true" decision if the strength of resonance quickly reaches some threshold or criterion level. However, if resonance is perceived to not be building quickly, or sufficient time has elapsed without the threshold's being reached, the subject responds "false." The problem-size or difficulty effect would occur because easy problems are based on strong problem-answer associations and quickly generate strong resonance, whereas the weaker associations underlying difficult problems build up resonance more slowly. Interference effects of close or related false answers would be due to the greater resonance produced by answers to be verified that are semantically near to the correct answer, which would make them difficult to discriminate from true equations and therefore difficult to reject as false.

Although the resonance model is plausible, Zbrodoff and Logan's (1990) interpretation of their results requires two assumptions: (1) that the delays tested were sufficient for subjects to complete retrieval before the verification answers appeared and (2) that similar processes mediate their number comparison task and the hypothetical answer comparison stage in Ashcraft's model. With respect to the first assumption, when Zbrodoff and Logan measured production RTs directly (Experiments 5-6), they found mean times for the larger number problems to be $946 \mathrm{msec}$ for addition and $1,494 \mathrm{msec}$ for multiplication. Thus, retrieval times for at least some of the larger, more difficult problems may sometimes exceed the maximum 1,000-msec answer delay tested in Experiments 1-2. Similarly, in their Experiments 3-4, mean times for subjects to be "ready" for the verification answer were in the $600-700 \mathrm{msec}$ range, much less than the production times observed in Experiments 5-6 (see Zbrodoff \& Logan, p. 93, for a discussion of this discrepancy). Consequently, the problemsize effects observed in Experiments 1-4 could have occurred because sometimes the verification answer appeared (and response timing began) before retrieval was finished.

The assumption that the number comparison task is equivalent to the comparison stage in the retrieve-compare model may also be questioned. Zbrodoff and Logan's (1990) number comparison task required subjects to make a same-different judgment about two numbers presented visually. In Ashcraft's retrieve-compare model, however, it is not physical representations of answers that are compared. Instead, it is the strengths of activation of the corresponding nodes in the network that are compared (e.g., Ashcraft, 1987, 1992), and that activation depends on the associative strength between the problem and presented answer. Ashcraft's model, therefore, does not necessarily predict equivalent split effects for the verification and number comparison tasks. Thus, although Zbrodoff and Logan's results clearly challenge the retrieve-compare model, it is worthwhile to test the 
comparability of production and verification in other ways.

\section{Production, Verification, and Error Priming}

Error priming refers to the phenomenon whereby arithmetic production errors are influenced by preceding problems. Because error priming apparently is due to residual activation of retrieval processes (Campbell, 1991), it may provide a useful tool for evaluating whether arithmetic production and verification involve the same retrieval processes. Error priming is observed when adults produce simple multiplication or addition answers under speed pressure. Speeded performance results in a substantial number of errors $(\approx 10 \%$ of trials $)$, most of which $(\approx 90 \%)$ involve correct answers to other simple arithmetic problems (e.g., $9 \times 6=36$ ). Error priming is evaluated by comparing the observed and expected frequencies with which errors match previous answers at different lags, where lag is defined as the number of trials between the error trial and the match trial.

Recent research has uncovered several interesting features of error priming (see Campbell \& Arbuthnott, in press, for a review). Campbell and Clark (1989) observed a curvilinear error-priming function with error-matching rates below chance for lag-of-1 matches (negative error priming), then rising above expected values over lags of about 2-10 trials (positive error priming) before returning to chance. The peak positive effect was approximately 2-3 times the expected value and occurred after lags of 4 or 5 trials (about $30 \mathrm{sec}$ ). Wheeldon and Monsell (1994) observed a similar curvilinear pattern of intertrial interference using a picture-naming task. Campbell and Clark proposed that negative and positive error priming reflect, respectively, inhibitory and excitatory processes activated on previous trials. The inhibitory process may function to counteract interference effects between trials that would arise from residual excitatory activation. According to Campbell and Clark, inhibition is initially stronger than excitation, which produces negative error priming, but inhibition decays more quickly, allowing the longer lasting excitatory effects of past processing to promote specific errors on later trials. The two effects are in equilibrium after 1-2 min, at which point error-matching rates return to chance levels.

Subsequent experiments indicated that positive error priming is diagnostic of answer retrieval processes and therefore provides a basis for discriminating retrievalbased and familiarity-based models of verification. Campbell (1991) demonstrated that naming an answer (e.g., saying "thirty-six" to 36 ) does not produce strong positive error priming, whereas retrieving an answer (e.g., producing "thirty-six" in response to $9 \times 4$ ) does strongly promote that answer as an error to subsequent problems. In other words, strong positive error priming was observed only when previous answers were retrieved. In the present research, we tested adult subjects on simple multiplication problems and alternated task type (verification or simple production) across trials. The primary analyses focused on intertrial error priming and examined the effects of previous verification and production trials on production-task errors and verification task errors. The retrieve-compare model of verification, which assumes that production and verification normally involve a common retrieval process, predicts that error priming will be as strong within as between trial types (i.e., production and verification trials). In contrast, if verification is based on familiarity and not on an answerretrieval process, as Zbrodoff and Logan's (1990) resonance model assumes, verification trials should not prime subsequent production errors and production trials should not prime later verification errors.

The present experiment included a group of control subjects who were tested with primed-production trials alternated with simple (i.e., unprimed) production trials. For primed production, a true or false numerical prime was presented for $200 \mathrm{msec}$ prior to presentation of the problem. The primed-production group provided a control for the possibility that the presented answer in verification could somehow disrupt error priming. For the primed-production trials, half of the primes were true and half were false, and the false-answer primes involved the same answers as those used for the false-verification equations.

\section{METHOD}

\section{Subjects}

Ninety-eight participants were recruited from a pool of volunteer undergraduate psychology students at the University of Saskatchewan. The sample included 63 females and 35 males, and ages ranged from 17 to 58 years $(M=20.3$, mode $=18)$. All subjects reported normal or corrected-to-normal vision. Forty-nine subjects were tested with trials alternating between verification and simple production (the verification group), and 49 received primed-production trials alternating with simple-production (the priming group). All subjects were tested in the same academic year, but testing of the verification group was completed before testing of priming subjects.

\section{Apparatus and Stimuli}

Stimuli were presented on two Panasonic C1391 color monitors connected to a Hewitt Rand 286 personal computer, with one monitor viewed by the subject and the other by the experimenter. White characters were presented against a dark background; each digit was $7 \mathrm{~mm}$ high $\times 3 \mathrm{~mm}$ wide. The subject sat approximately $50 \mathrm{~cm}$ from the monitor. A lapel microphone activated a relay switch connected to the computer's serial port. The voice-operated relay provided the stop signal for a software clock accurate to $\pm 1 \mathrm{msec}$.

Stimuli were the 36 multiplication problems composed from combinations of the numerals 2 through 9 . Each problem was assigned both a related and an unrelated false answer that were used for both the verification and primed-production tasks. The falseanswer assignments were the same as those used by Campbell (1991) and Meagher and Campbell (1995; see the Appendix). Related false answers were from the same times table as the presented problem (i.e., the answer was a multiple of at least one of the problem's operands; e.g., 24 for $4 \times 8$ ). Unrelated answers were not multiples of either of the problem's operands, but were correct for another of the multiplication problems tested (e.g., 27 for $4 \times 8$ ). The split (i.e., the absolute numerical distance between a presented answer and the problem's correct answer) was approx- 
imately equated for related and unrelated answers. ${ }^{1}$ Odd/even agreement between presented answers and correct answers was also balanced for related and unrelated answers.

\section{Design}

Verification subjects received 2 sets of 4 blocks of 72 multiplication trials. Odd-numbered trials involved verification and evennumbered trials involved production. For verification, each problem was presented with an answer to be verified as true or false (e.g., $2 \times 3=12$ ). Production trials consisted of a problem followed by a question mark (e.g., $2 \times 3=$ ?). Each 4-block set had the following design: Within each block, all 36 problems were tested once under production and once under verification conditions. There were 18 true and 18 false-verification equations in each block, and half the false equations were presented with related false answers and half with unrelated false answers. Across the 4 blocks, each of the 36 problems was tested twice in a trueverification equation and once with a related false and once with an unrelated false answer. The order of verification conditions across blocks was determined by randomly assigning for each subject 3 problems to each of the 12 unique orders of conditions (TTRU, TTUR, RTTU, UTTR, RUTT, URTT, TRTU, TUTR, RTUT, UTRT, TRUT, TURT, where $\mathrm{T}=$ true, $\mathrm{R}=$ related, and $\mathrm{U}=$ unrelated). Order of problems within each block was randomized with the constraint that verification and production trials involving the same problem were separated by at least 18 trials. The problem set includes 8 "ties" $(2 \times 2,3 \times 3,4 \times 4$, etc. $)$ and 28 nonties $(2 \times 3,8 \times 4$, etc. $)$. For each of the production and verification tasks, approximately half of the non-tie problems were randomly selected to be tested with the smaller number on the left in the first block. Operand order then alternated across blocks.

The experimental design for priming subjects was identical to that for verification subjects except that priming subjects received primed-production trials (rather than verification) alternating with simple-production trials. For primed-production trials, a presented answer (i.e., a true or false prime) appeared for $200 \mathrm{msec}$ before the problem appeared (e.g., 6 followed by $2 \times 3$ ). False primes were the same related and unrelated false answers as those used for verification (see the Appendix), and all other details of balancing and randomization were the same as those for verification subjects.

\section{Procedure}

Subjects were tested individually in a $1-\mathrm{h}$ session that included a warm-up task and the main experimental task. The testing room was dimly lit to reduce reflected images on the display screen and the experimenter was out of the subject's immediate field of vision to minimize distractions. In the warm-up, the subject received a series of digit-naming trials involving the Arabic numerals 1-40 presented individually in a random order at the center of the screen. Subjects were instructed to respond as quickly as possible. On each trial, a fixation dot appeared at the center of the screen and then flashed twice over a l-sec interval. On what would have been the third flash, the number to be named appeared on the screen with the right-most digit at fixation. After each naming response, the screen was blank for $300 \mathrm{msec}$, and then the fixation dot for the next trial appeared.

Instructions for the arithmetic task stressed the importance of speed and accuracy with an emphasis on speed. Subjects were told that occasional errors were inevitable with speeded responding and that such errors were of no concern. The purpose of these instructions was to foster speed-accuracy criteria that would produce a relatively large error rate, because a large number of errors is necessary for statistically reliable analysis of error priming. The testing program allowed the experimenter to monitor subjects' error rates and, between blocks, the experimenter occasionally encouraged subjects to speed up in order to obtain more errors.

Verification subjects were instructed to verbally respond "true" or "false" for verification trials and to state the correct answer for production trials. They were informed that a random half of the verification equations would be true. The prompt "TRUE or FALSE" appeared in the top half of the screen before each verification trial and the word "ANSWER" appeared before each production trial. Before each trial, a fixation dot appeared at the center of the screen below the prompt, and then flashed twice over a $1-\mathrm{sec}$ interval. The prompt disappeared when the dot began to flash, and on what would have been the third flash, the problem appeared in horizontal orientation on the screen with the right-most operand at fixation. Timing began when the problem appeared and the timer was stopped when the subject's verbal response triggered the voice-operated relay. The spoken response caused the problem to immediately disappear from the screen, which allowed the experimenter to detect and record failures of the voice-activated relay. Provided that the experimenter entered the response within $1.5 \mathrm{sec}$, the response-stimulus interval was $3 \mathrm{sec}$.

Priming subjects were asked to state the correct answer for both primed-production and simple-production trials. For each trial, a fixation dot appeared at the center of the screen and then flashed twice over a 1 -sec interval. For primed-production trials, the prime replaced the fixation dot with the right-most digit at fixation and remained on the screen for $200 \mathrm{msec}$. The target problem was then presented horizontally with the multiplication sign at the fixation point. For unprimed-production trials, the target problem appeared on what would have been the third flash of the fixation dot with the multiplication sign at fixation. All subjects received a brief rest period of approximately $1 \mathrm{~min}$ between blocks.

\section{RESULTS}

\section{Arithmetic Performance}

Failures of the voice-activated relayed spoiled $1.7 \%$ of RTs. Another $3.0 \%$ of RTs greater than 2.5 standard deviations from a subject's grand mean per condition were discarded as outliers. Table 1 presents the mean RT for correct trials and percentage of errors for each condition. For completeness, Table 1 includes a breakdown of the results for "Easy" and "Difficult" problems (see following section) but the main analyses were based on "All" problems. RTs and errors were analyzed using 2 (group) $\times 4$ (condition) analyses of variance (ANOVAs). The overall mean RT was longer for the verification group $(927 \mathrm{msec})$ than for the priming group $(799 \mathrm{msec})[F(1,96)=26.86$, $\left.M S_{\mathrm{e}}=59,922, p<.001\right]$. RTs also varied as a function of condition $\left[F(3,288)=172.66, M S_{\mathrm{e}}=2,255, p<.001\right]$, and the effects of condition on RT varied between groups $\left[F(3,288)=32.60, M S_{\mathrm{e}}=2,255, p<.001\right]$. For the verification group, only the RT difference between simple production and true verification was not significant (Tukey's honestly significant difference $[\mathrm{HSD}]=33.61, p=$ $.01)$. For the priming group, only the RT difference between related false and unrelated false conditions was not significant $(\mathrm{HSD}=27.10, p=.01)$. Error rates did not differ overall between the verification $(13.6 \%)$ and priming $(15.6 \%)$ groups $\left[F(1,96)=1.73, M S_{\mathrm{e}}=210.84\right.$, $p=.19]$. Error rates varied substantially across conditions $\left[F(3,288)=135.34, M S_{\mathrm{e}}=48.12, p<.001\right]$, however, and the effects of condition depended on group $\left[F(3,288)=24.22, M S_{\mathrm{e}}=48.12, p<.001\right]$. Specifically, verification subjects made more errors of related false verification relative to all other conditions, and there were no other significant differences (HSD $=4.15, p=$ 
Table 1

Means and Standard Errors for Correct Response Time (in Milliseconds) and Percentage of Errors for Each Group and Task for Easy, Difficult, and All Problems

\begin{tabular}{|c|c|c|c|c|c|c|c|c|}
\hline \multirow[b]{4}{*}{ Group } & \multicolumn{8}{|c|}{ Task } \\
\hline & & & \multicolumn{6}{|c|}{ Verification/Primed Production } \\
\hline & \multicolumn{2}{|c|}{ Simple Production } & \multicolumn{2}{|c|}{ True } & \multicolumn{2}{|c|}{ Unrelated } & \multicolumn{2}{|c|}{ Related } \\
\hline & $M$ & $S E$ & $M$ & $S E$ & $M$ & $S E$ & $M$ & $S E$ \\
\hline \multicolumn{9}{|c|}{ Response Time } \\
\hline \multicolumn{9}{|l|}{ Verification } \\
\hline Easy & 794 & 13 & 854 & 16 & 910 & 15 & 978 & 19 \\
\hline Difficult & 968 & 27 & 946 & 20 & 962 & 22 & 1029 & 25 \\
\hline All & 875 & 19 & 897 & 17 & 934 & 18 & 1003 & 21 \\
\hline \multicolumn{9}{|l|}{ Priming } \\
\hline Easy & 728 & 11 & 667 & 11 & 821 & 15 & 818 & 15 \\
\hline Difficult & 841 & 27 & 744 & 26 & 924 & 28 & 930 & 29 \\
\hline All & 773 & 16 & 698 & 16 & 863 & 19 & 863 & 20 \\
\hline \multicolumn{9}{|c|}{ Percentage of Errors } \\
\hline \multicolumn{9}{|l|}{ Verification } \\
\hline Easy & 3.0 & 0.4 & 5.9 & 0.7 & 7.0 & 1.0 & 19.5 & 1.9 \\
\hline Difficult & 17.8 & 1.4 & 16.0 & 1.3 & 10.7 & 1.3 & 29.1 & 2.0 \\
\hline All & 10.4 & 0.8 & 11.0 & 0.9 & 8.8 & 1.1 & 24.3 & 1.8 \\
\hline \multicolumn{9}{|l|}{ Priming } \\
\hline Easy & 3.7 & 0.7 & 1.6 & 0.3 & 9.5 & 1.6 & 15.8 & 2.0 \\
\hline Difficult & 20.3 & 1.7 & 6.1 & 1.0 & 27.2 & 2.1 & 40.5 & 2.5 \\
\hline All & 12.0 & 1.1 & 3.8 & 0.6 & 18.3 & 1.7 & 28.2 & 2.1 \\
\hline
\end{tabular}

$.01)$. For priming subjects, error rates in all four conditions differed from each other $(\mathrm{HSD}=4.75, p=.01)$. As observed in previous primed-production studies (Campbell, 1991; Meagher \& Campbell, 1995), the higher error rate with related primes $(28.2 \%)$ than unrelated primes $(18.3 \%)$ was due to prime intrusions, that is, errors where the incorrect answer corresponded to the prime presented on that trial. ${ }^{2}$ Prime intrusions also accounted for the overall differences in error rates among the related, unrelated, and simple production conditions for the priming group. When errors corresponding to a problem's assigned primes were excluded, the rate of "other" errors was similar across conditions $(8.3 \%, 9.4 \%$, and $9.3 \%$ for related, unrelated, and simple production, respectively).

The results generally replicated previous findings, but there was an unexpected result associated with the simple-production data. Whereas the two groups produced similar error rates on the simple-production trials $(10.4 \%$ and $12.0 \%)$, verification subjects produced substantially longer RTs than those of the priming subjects in the simple-production condition ( $875 \mathrm{vs} .773 \mathrm{msec})$. This difference may have arisen because alternating response types for verification subjects (i.e., production or verification) introduced a response-type selection process not required by priming subjects, who produced a numerical answer on all trials. In support of this hypothesis, verification subjects sometimes stated a numerical answer on verification trials $(M=3.7$ times per subject) rather than stating "true" or "false." These production intrusions occurred about equally often for true (97) and false (83) equations. Seventy-three percent (131) of the production intrusions occurred on the easier, small number problems with both operands less than or equal to 5 . This suggests that the probability of a production intrusion was higher when the correct numerical answer was highly accessible (LeFevre, Bisanz, \& Mrkonjic, 1988).

Effects of problem difficulty. We also performed ANOVAs that included problem difficulty as a factor, using Campbell's (1987) division of multiplication problems into "easy" and "difficult" sets (see also Campbell, 1991; Meagher \& Campbell, 1995). The easy problems include most of the "ties" (e.g., $4 \times 4=16$ ) and smallnumber problems (e.g., $2 \times 3=6$ ) whereas the difficult problems are mostly composed of large-number problems (e.g., $6 \times 9=54$ ) (see the Appendix). Differences in problem difficulty are presumed to reflect differences in either the type or the efficiency of computational processes. Ashcraft et al. (1984) found comparable difficulty effects for the verification and production tasks, which is consistent with the hypothesis that the two tasks are based on a common answer retrieval process. Table 1 includes the mean RTs and percentages of errors separately for easy and difficult problems for each condition. In the present experiment, all group $\times$ condition cells showed a difficulty effect, but the three-way interaction of group, condition, and difficulty was significant for both RTs $\left[F(3,288)=22.13, M S_{\mathrm{e}}=1,877.47, p<.001\right]$ and errors $\left[F(3,288)=42.37, M S_{\mathrm{e}}=28.64, p<.001\right]$. Because the form of the three-way interactions was complex and did not appear to support unique conclusions beyond those derived from the effects of group and condition, we focused on interpreting the simpler two-factor (group $\times$ condition) analysis described in the preceding section.

However, there was a potentially important result in the analysis that included difficulty as a factor: For the 
verification group, the difficulty effect (i.e., the difference between difficult and easy problems) was substantially larger in the simple-production $(+174 \mathrm{msec},+14.8$ percentage of errors) than the verification conditions ( $+65 \mathrm{msec},+7.8$ percentage of errors). For the priming group, the difficulty effect was similar in the simpleproduction $(+113 \mathrm{msec},+16.6$ percentage of errors $)$ and the primed-production conditions $(+97 \mathrm{msec},+15.6$ percentage of error). The task $\times$ difficulty interaction observed for the verification group is not predicted by the retrievecompare model, which assumes that verification and production are based on the same retrieval process. ${ }^{3}$

Summary of arithmetic performance. Because the pattern of results is relatively complicated, it is worth summarizing the analyses of RT and error rates. For the verification group, latencies on simple-production trials and true-verification trials were not significantly different. In contrast, the priming group was faster on trials with true primes (e.g., 54 and $6 \times 9$ ) than on trials without a prime, indicating that presentation of the answer facilitated production. Verification subjects were slower on false trials than on either production or true-verification trials, and they verified unrelated false trials significantly more quickly than they verified related false trials. In contrast, for the priming group, related and unrelated false primes did not differentially affect latencies, although both were solved more slowly than unprimed or trueprimed trials. The latency results in the priming group indicate that true primes facilitate processing relative to an unprimed condition, but that false primes interfere with successful retrieval. The error rates for the priming group support this interpretation. The error rates in the four conditions were all significantly different. The fewest errors were made when the correct answer was primed and the most errors were made when a related false answer was primed. For the verification group, however, only the related false condition produced more errors than the other three conditions, which were not significantly different. In addition to different effects of presented answers for verification and production, the problem difficulty effect was substantially greater in production than verification. In the Discussion, we propose that these task-related differences arise because verification and production emphasize different memory processes; specifically, we propose that production is primarily retrieval based, whereas verification is primarily familiarity based. The error-priming analyses described next provide converging evidence that arithmetic verification and production involve different computational processes. We first describe error priming in the production task and then report analyses of intertrial priming of verification errors.

\section{Intertrial Priming of Production Task Errors}

Error priming in the production task was analyzed by matching incorrect responses made on simple-production trials to previous answers within each block of trials. Of the 3,159 simple-production errors, $2,831(89.6 \%)$ involved correct answers to other problems tested and there- fore were potentially matchable. A computer program searched back through previous trials from each matchable error. The program attempted to match errors to (1) the correct answer to previous simple-production problems, (2) the correct answer from true-verification trials (verification subjects) or true primed-production trials (priming subjects), (3) the correct answer from false-verification trials (verification subjects) or from false-primed triais (priming subjects), and (4) the presented answer from false-answer verification (verification subjects) or priming trials (priming subjects).

For each subject, the analysis program tallied the frequency of each type of match for each lag. Because of the interleaving of simple-production trials with verification (verification subjects) or primed production (priming subjects), we defined lag in terms of the number of trials of the same type separating an error and a previous answer. For example, in the case of matching a simpleproduction error with a verification answer, a lag of 1 refers to a match with the verification trial immediately preceding the error. A lag of 2 for a verification match refers to the next-to-last verification trial, not counting the simple-production trial that intervened between the first and second previous verification trials. Similarly, for an error matching a previous simple-production trial, a lag of 1 refers to the first previous simple-production trial, ignoring the intervening verification trial, a lag of 2 refers to the second previous simple-production trial, a lag of 3 to the third previous simple-production trial, and so on, not counting the interleaved verification trials.

The error-priming analysis program also computed an appropriate baseline for each match type. Error-matching frequencies expected by chance were estimated by randomizing the order of trials in each block and performing the error-matching analyses on the randomized sequences. For each subject, mean expected error-matching values for each lag for each match type were computed on the basis of 100 such randomizations. In order to keep the number of answer-error matching opportunities at each lag the same in the randomized and original data, the baseline program (1) searched back from the original trial position of each error and (2) avoided relocating an answer that would match a specific error into the original trial position occupied by the error, because this would eliminate a matching opportunity that existed in the original problem sequence.

The results for the verification group appear in Figure 1, which shows for each match type the mean percentage of deviation from expected error-matching frequencies (and 95\% confidence interval) for a lag of 1 , lags of 2-5 trials, and lags of 6-20 trials. The corresponding results for the priming group appear in Figure 2. The lag-of-1 data demonstrate negative error priming and will be analyzed separately. The lag range of 6-20 represents longer lags where we expected to observe no error priming. A lag of 5, which corresponds to 10 or 11 intervening trials, was chosen as the cutoff for positive error priming because previous research has indicated that this is about the maximum range of the effect 
(e.g., Campbell, 1991; Campbell \& Arbuthnott, in press; Campbell \& Clark, 1989). Subjects with very low expected matching frequencies (less than .01) in any cell were treated as missing cases in the corresponding analysis.

\section{Positive Priming of Production Errors}

Positive error priming was analyzed by comparing the magnitude of the deviation scores over lags of 2-5 with lags of 6-20. We included the error-matching data for presented false answers in Figures 1 and 2 for completeness; however, false presented answers produced no evidence of positive error priming for either group (see also Campbell, 1991). Consequently, we analyzed positive error priming in a $2 \times 2 \times 3$ mixed-factor ANOVA with factors of group (verification and priming), lag (2-5 vs. 6-20), and match type (correct answers from previous production, true trials, or false trials). The ANOVA demonstrated a main effect of lag $\left[F(1,95)=47.02, M S_{\mathrm{e}}=\right.$ $6,129.84]$ and match type $\left[F(2,190)=4.40, M S_{\mathrm{e}}=6,554\right.$, $p=.014]$, and the lag $\times$ type interaction $[F(2,190)=$ 4.40, $\left.M S_{\mathrm{e}}=9,675, p=.014\right]$. As Figures 1 and 2 show, the lag $\times$ type effect occurs because error-matching rates for some match types were greater than chance over short lags (demonstrating positive error priming), but there was no evidence of error priming over greater lags (i.e., for both groups, a mean deviation of $0 \%$ fell within the $95 \%$ confidence interval for all match types over lags of 6-20).

The lag $\times$ type interaction was qualified by the threeway interaction involving group $\left[F(2,190)=3.97, M S_{\mathrm{e}}=\right.$

\section{VERIFICATION GROUP / PRODUCTION ERRORS}

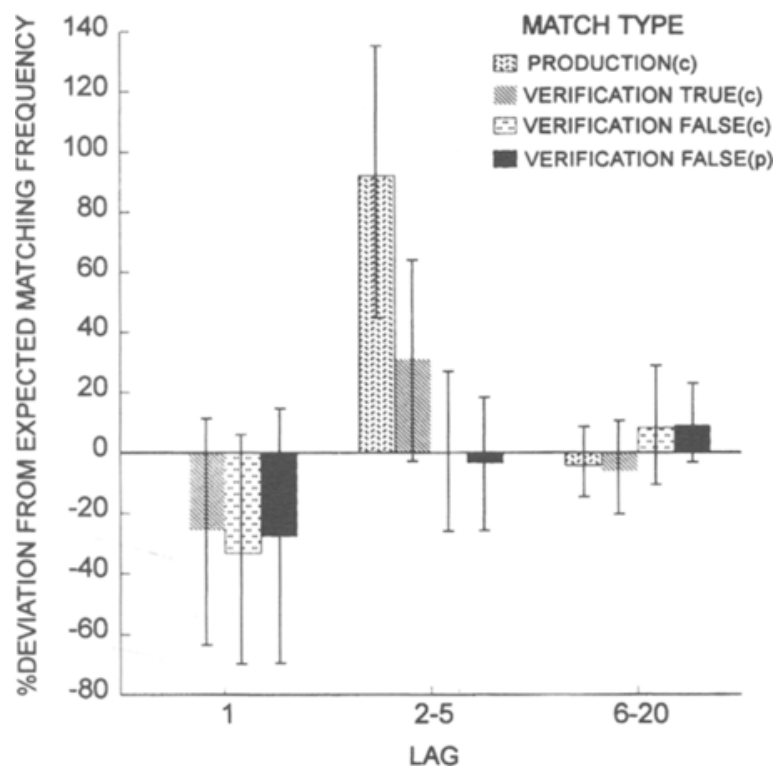

Figure 1. Mean percentage of deviation from expected production error-matching frequency as a function of match type and lag for the verification group. For match type, $(\mathbf{c})=$ match correct answer, $(p)=$ match-presented answer. Error bars represent the $95 \%$ confidence intervals for the means.

\section{PRIMING GROUP / PRODUCTION ERRORS}

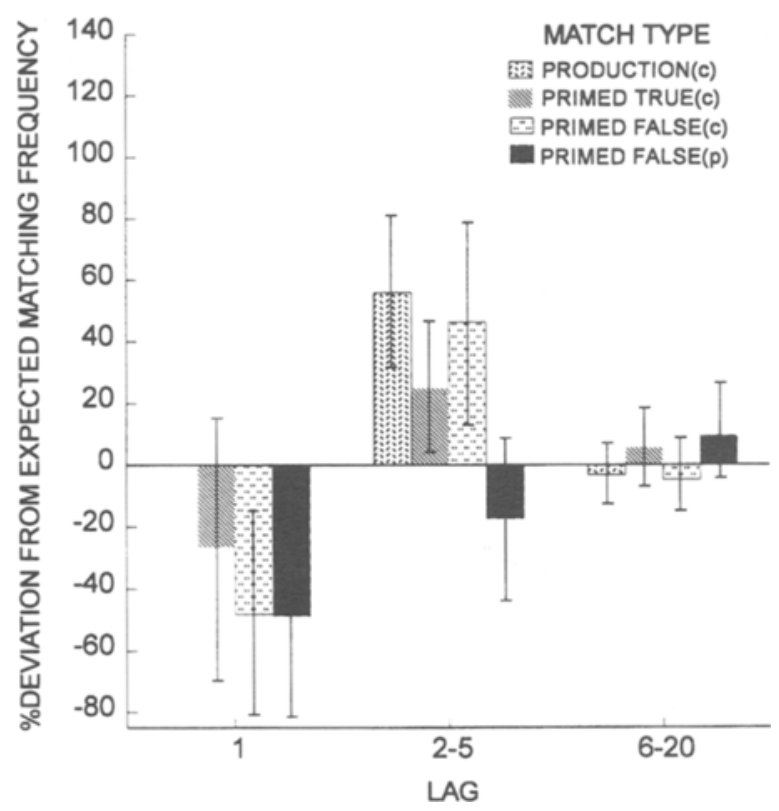

Figure 2. Mean percentage of deviation from expected production error-matching frequency as a function of match type and lag for the priming group. For match type, $(c)=$ match correct answer, $(p)=$ match-presented answer. Error bars represent the $95 \%$ confidence intervals for the means.

$9,675, p=.021]$. We decomposed the three-way interaction by performing separate group $\times$ match type ANOVAs at each level of the lag factor. As expected, given no evidence of error priming over the longer lags, there were no significant effects in the analysis of lags of 6-20 (largest $F=1.62, p=.20$ ). In the analysis of lags $2-5$, however, both the effect of match type $[F(2,190)=$ $\left.5.26, M S_{\mathrm{e}}=13,447, p=.006\right]$ and the group $\times$ match type interaction were significant $\left[F(2,190)=3.78, M S_{\mathrm{e}}=\right.$ $13,447, p=.025]$. Thus, the three-way interaction occurred because effects of match type varied as a function of group, but only over shorter lags.

Specifically, verification subjects' error-matching rates differed significantly as a function of match type over lags of 2-5 $\left[F(2,96)=5.93, M S_{\mathrm{e}}=18,020, p=.004\right]$. As Figure 1 shows, a mean deviation of $0 \%$ fell below the lower bound of the $95 \%$ confidence interval only for simpleproduction matches, although the data are also suggestive of a relatively weak positive error-priming effect from true-verification trials. There was no positive error priming from false-verification trials. A Tukey's test indicated that errors matched simple production answers more often than false-verification answers $(p<.01)$, but that matches with true-verification answers over lags of 2-5 did not differ from those in the other two conditions $(p>$ .05 ). Overall, however, simple production produced stronger error priming than true- and false-verification conditions combined $\left[F(1,48)=7.12, M S_{\mathrm{e}}=21,326, p=\right.$ $.01]$. This evidence that error priming is task specific is 
consistent with Zbrodoff and Logan's (1990) resonance model, which assumes that the production and verification tasks are based on different retrieval processes.

For priming subjects, a mean deviation of $0 \%$ fell below the lower bound of the $95 \%$ confidence interval for all three match types, confirming a positive errorpriming effect for the three types over lags of $2-5$. In contrast to the verification group, there were no significant effects of match type for priming subjects over lags of $2-5\left[F(2,94)=1.77, M S_{\mathrm{e}}=8,777, p=.176\right]$. Thus, the results for the priming group suggest that simpleproduction and true- and false-primed production produce equivalent positive error priming. More generally, these data indicate that presenting an answer (i.e., the prime) with a problem does not disrupt its capacity to produce positive error priming. Therefore, the weak error priming from verification trials demonstrated by verification subjects cannot simply be attributed to disruptive effects of encoding the presented answer.

Because differences between the groups in positive error priming appeared to be associated with verification versus primed production, we conducted a separate analysis of these conditions. The group $\times$ true/false match type interaction was significant $\left[F(1,95)=5.76, M S_{\mathrm{e}}=7,842\right.$, $p<.018$ ]. The interaction occurs because, whereas positive error priming from true-primed production and false-primed production did not differ for the priming group $\left[F(1,47)=2.04, M S_{\mathrm{e}}=10,576, p=.16\right]$, there was significantly greater positive error priming from trueverification than from false-verification trials for the verification group $\left[F(1,48)=4.58, M S_{\mathrm{e}}=5,166, p=\right.$ $.037]$. This difference confirms that there was some, albeit relatively weak, positive error priming produced by true-verification trials.

In summary, for both the verification and priming groups, positive priming of production errors was observed over lags of 2-5 (i.e., 10 or 11 trials due to the interleaved trial types), but there were important differences between the groups. For priming subjects, previous simple-production, true-primed production, and falseprimed production trials produced more or less equivalent error priming. For verification subjects, however, positive error priming differed significantly as a function of match type. Specifically, whereas there was strong positive priming from previous simple-production trials, there was only weak evidence of positive error priming from previous verification trials. True trials appeared to produce some positive error priming, but there was no positive error priming observed in connection with falseverification trials. The results demonstrate that encoding a problem without necessarily generating an answer (i.e., as in the false-verification trials) is not sufficient to produce positive priming of production errors. Thus, it is unlikely that positive error priming is due to residual priming of encoding processes. Furthermore, although the effects of presented answers on RT and percentage of errors in both the verification and primed-production tasks confirm that the presented answers received substantial processing, no positive error priming was observed in con- nection with previously presented answers. This extends previous work demonstrating that strong positive error priming is not produced by answers that are encoded or named only and not retrieved (Campbell, 1991). The results support the conclusion that positive error priming in the production task arises in retrieval processes (e.g., priming or consolidation of problem-answer associations) as opposed to more peripheral problem encoding or response processes.

\section{Negative Priming of Production Errors}

Negative error priming refers to the phenomenon in which errors match the answer from the immediately preceding trial less often than expected by chance. Figures 1 and 2 include the mean percentage of deviation from chance for a lag of 1 as a function of match type. We excluded the simple-production condition because the first matching opportunity for simple-production trials always involved an intervening verification or primed-production trial, and negative error priming effects decrease rapidly with time (Arbuthnott \& Campbell, in press; Campbell \& Arbuthnott, in press; Campbell \& Clark, 1989). Thus, we analyzed only matches with verification or primed-production trials in which answer matches with the immediately preceding trial were possible (i.e., true [correct answer], false [correct answer], and false [presented answer]). The design of the analysis was a 3 (match type) $\times 2$ (group) $\times 2$ (observed vs. expected) mixed-factor ANOVA. Observed error-matching rates for lag-of- 1 were lower than expected $\left[F(1,96)=5.90, M S_{\mathrm{e}}=0.31, p=.017\right]$, which demonstrates negative error priming, but there were no effects associated with either type or group (all other $F \mathrm{~s} \leq 1.05)$. On average, the error-matching rate for lag E-1 was $35 \%$ below the expected value. This analysis demonstrates that negative error priming occurred in association with both previous verification and primedproduction trials, and that both the correct and presented answers from the immediately preceding trial were inhibited as error responses.

The finding of negative priming, but not positive priming, in connection with the correct answer from falseverification equations suggests that the correct answer is accessed on false-verification trials but that either it is not activated strongly enough for positive error priming or it is not processed in the same way as in the production task. The following analysis, which compares intertrial priming of production and verification errors, supports the conclusion that the production and verification tasks engage different memory processes.

\section{Intertrial Priming of False-Verification Errors}

For the preceding analysis of error priming in the production task, we matched specific incorrect answers to previous answers, whereas the verification task provides only a response of "true" or "false" for each trial. Nonetheless, it is possible to analyze error priming for incorrect false-verification trials by matching the presented false answer to previous correct answers. The purpose is 
to determine if errors on false-verification trials (e.g., responding "true" to $3 \times 9=18$ ) are more likely if the presented false answer (i.e., 18) was the correct answer to a previous problem. The retrieve-compare model predicts that if such priming is observed, it should be as strong for previous production trials as it is for previous verification trials (i.e., responding "true" to $3 \times 9=18$ should be equally primed by previously processing $3 \times 6=$ ? or $3 \times 6=18$, true or false?). This follows from the assumption that both tasks involve a common answer retrieval stage that is the origin of error priming. However, if verification and production involve different retrieval processes we would expect stronger priming of verification errors from previous verification trials than from previous production trials. That is, the pattern of error priming from verification and production trials should be reversed for verification errors relative to that observed for production errors.

The analysis of the priming of verification errors was performed in the same manner as the analysis of the priming of production errors. Of the 1,183 false-verification errors, $74 \%$ occurred in the related false condition. Figure 3 shows the mean percentage of deviation from expected matches for lag of 1, lags of 2-5 trials, and lags of 6-20 trials. At a lag-of- 1 , verification errors can only match simple-production answers (i.e., because of the interleaving of production and verification trials, verification problems were separated by a minimum lag of 2 trials). As the lag-of- 1 data in Figure 3 show, there was no evidence of negative error priming in connection with the production trial immediately preceding a false-verification error.

\section{Positive Priming of False-Verification Errors}

Figure 3 shows that for lags greater than 1 , there was no evidence that the presented false answers produced intertrial priming of verification errors. Consequently, we analyzed positive error priming in a $2 \times 2 \times 3$ repeated measures ANOVA with factors of task (false-verification errors or production task errors; i.e., Figure 3 vs. Figure 1), lag (2-5 or 6-20), and match type (correct answers from previous production, true, or false trials). The task $\times$ lag $\times$ type interaction $\left[F(2,96)=6.23, M S_{\mathrm{e}}=8,957\right.$, $p=.003]$ was decomposed with separate task $\times$ match type ANOVAs for each level of the lag factor. For lags 6-20, there were no significant effects $(F \mathrm{~S}<1)$, and there was no positive error priming for either false-verification errors or production errors. For lags $2-5$, the overall magnitude of positive error priming was greater for production errors than for false-verification errors $[F(1,48)=$ $\left.4.64, M S_{\mathrm{e}}=12,751, p=.036\right]$, and the pattern of error priming as a function of match type was different for the two tasks $\left[F(2,96)=8.09, M S_{\mathrm{e}}=12,199, p=.001\right]$. Whereas production errors (Figure 1) were more strongly primed by previous production trials than by verification trials, verification errors (Figure 3 ) were not primed by previous production trials, but there was evidence that false-verification errors were primed by previous verification trials. Both previous true trials $[t(48)=1.77, S E=$

\section{VERIFICATION GROUP / VERIFICATION ERRORS}

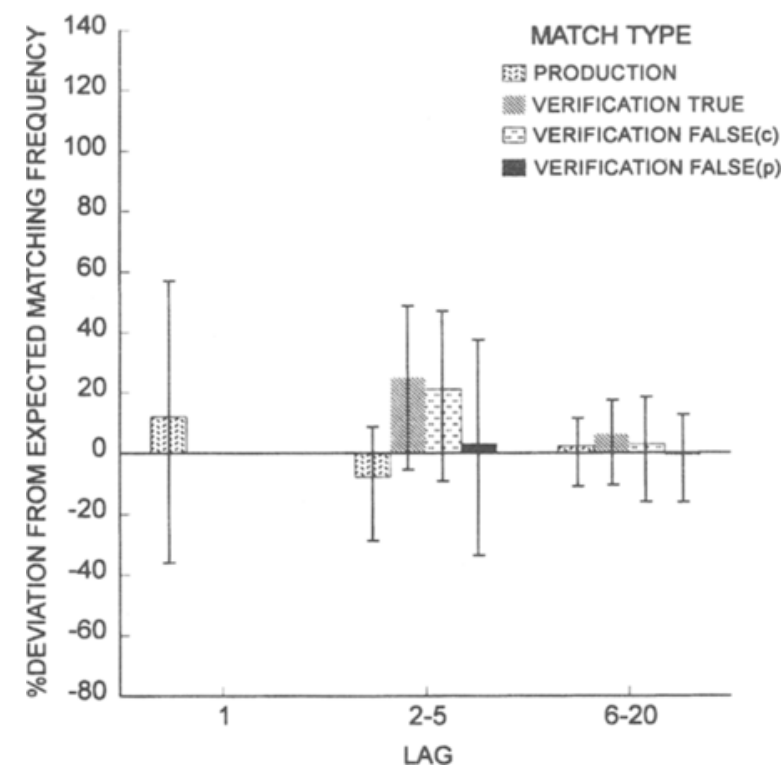

Figure 3. Mean percentage of deviation from expected falseverification error-matching frequency as a function of match type and lag for the verification group. For match type, $(c)=$ match correct answer, $(p)=$ match-presented answer. Error bars represent the $95 \%$ confidence intervals for the means.

$14.3, p=.039$, one-tailed $]$ and previous false trials $[t(48)=$ $1.51, S E=14.0, p=.067$, one-tailed] tended to promote subsequent verification errors, although these effects were relatively weak. Nonetheless, overall there was significant priming of verification errors by previous verification trials: For true and false match types combined, the mean deviation from chance was $+24.9 \%[t(48)=$ $2.59, S E=9.6, p=.006$, one-tailed], and this effect was significantly greater than that for priming of verification errors by previous production trials $[t(48)=2.87, S E=$ $11.4, p=.006$, two-tailed]. The results indicate a clear dissociation between error priming in the production and verification tasks: Production errors were strongly primed by previous production trials over lags of $2-5$ trials, but not by verification trials, whereas verification errors were primed by previous verification trials but not by production trials.

\section{DISCUSSION}

The Discussion is divided into four sections. We first discuss implications of our findings for positive and negative error priming. We then discuss the implications for theories of arithmetic verification and conclude that the results support a resonance- or familiarity-based model over a retrieval-based model. We next turn to the primedproduction data and argue that the performance differences between primed production and verification reflect the different underlying computational processes (i.e., answer retrieval and familiarity assessment, respectively). 
Finally, we reconsider the retrieve-compare model of arithmetic verification and observe that, although the model does not predict several of our findings, it may be applicable under a variety of circumstances.

\section{Positive Error Priming}

The present experiment is the first to demonstrate error priming outside of the production task. The data demonstrate positive priming of false-verification errors when the presented false answer is the correct answer to a previous true- or false-verification trial. That is, there was an increased likelihood, for example, of a subject responding "true" to $6 \times 8=72$ if either $9 \times 8=72$ or $9 \times 8=$ 63 was encountered within the preceding 10 or 11 trials. This implies that the correct answer was activated in some way by both true- and false-verification equations. This conclusion is also supported by the observation of negative error priming of the correct answer for both true and false equations (e.g., subjects were unlikely to produce 72 as an error if the preceding trial involved either $9 \times 8=72$ or $9 \times 8=63$ ). However, although these results imply that the correct answer was processed even for false-verification trials, this processing did not prime production-task errors involving that answer. Strong intertrial priming of production errors was observed only in connection with previous production trials. Conversely, retrieving an answer in the production task did not prime errors on false-verification equations involving that answer (e.g., responding correctly to $9 \times 8=$ ? did not increase the probability of subsequently responding "true" to $6 \times 8=72$ ). Thus, although activation of the correct answer is implicated for both the verification and production tasks, intertrial priming of errors involving the correct answer was task specific. These results cannot be explained simply by assuming that verification and production involved different amounts of activation of the correct answer and that positive error priming varies as a function of this activation. In contrast to the taskspecific error priming observed, this hypothesis predicts that whichever task produces stronger activation of the correct answer should consistently produce the strongest priming of both production and verification errors. Instead, the results indicate that positive error priming in the production and verification tasks arises independently in processes that either are not shared by the two tasks or are not engaged in the same way by the two tasks.

On the basis of the finding of task-specific error priming (and other evidence discussed below), we conclude that production and verification in the present experiment were based on different types of memory processes; specifically, we propose that whereas production necessarily involved answer retrieval, verification was usually based on a judgment of global familiarity. On this view, task-specific error priming occurs because these two memory strategies have distinct consequences in terms of the processes that are activated and strengthened. Although the correct answer is activated on verification trials, its link to verbal production mechanisms may not be strengthened as much as when the task actu- ally requires production of a verbal response. In this case, erroneous verbal productions would not be primed as strongly by previous verification trials as by previous production trials. In contrast, we assume that verification performance in the present experiment hinged on distinguishing the global familiarity produced by correct equations from that produced by incorrect equations. Judging the familiarity of one equation (e.g., $7 \times 9=63$ ) may increase the perceived familiarity of a subsequent equation (e.g., $6 \times 9=63$ ) if the presented answer is correct for a previous problem. When two equations with common or related components (e.g., $7 \times 9=56$ and $6 \times$ $9=63$ ) are assessed relatively close in time, there may be combinatorial activation that creates an illusion of enhanced familiarity or fluency for the second equation (see Reder, 1987; Reder \& Ritter, 1992). Alternatively, subjects may associate correct verification answers with the "true" response, causing a residual bias to perceive as "true" a false equation with a presented answer that was correct for a previous equation. Arithmetic production trials would not prime verification errors in this way because subjects do not make familiarity judgments on production trials, which reduces the common, transferappropriate processing that could bias familiarity assessment on a later verification trial.

What might explain the stronger priming of production errors by true- relative to false-verification trials? Although performance of verification may not require answer retrieval, spontaneous answer retrieval may be more likely for true than for false verification. When the answer to be verified is correct and therefore highly associated with the presented problem, priming by the problemanswer combination might sometimes cause answer retrieval processes to run to completion as they do in the production task. The strong facilitation observed with correct-answer primes in the arithmetic production task (e.g., Campbell, 1987, 1991; see also results for the priming group in Table 1) suggests that presenting the correct answer can prime its retrieval. Thus, if positive error priming in the production task is promoted when answers are actually retrieved on previous trials, a higher probability of answer retrieval for true equations would lead to stronger positive error priming for true than for false equations. However, if true-verification equations prime retrieval of the correct answer, it is likely that subjects sometimes compare the retrieved and presented answer to determine whether the equation is true or false. Thus, true verification may be mediated both by answer retrieval and familiaritybased strategies, whereas false verification is based more consistently on familiarity or resonance.

Another possible factor in the stronger priming of production errors by true than by false equations is that memory for true equations may be consolidated (e.g., rehearsed or otherwise integrated), whereas equations classified as false may not receive additional processing. This would lead to greater strengthening of the encoded problem-answer associations for true equations than for false equations. In Campbell's (1995) network interference model of number fact retrieval, a strengthening pro- 
cess underlies positive error priming in the production task. Specifically, problem nodes are assumed to be composed of associated components (i.e., the operand pair, operation sign, and answer) that are activated and retrieved as a unit (see also Rickard, Healy, \& Bourne, 1994). The capacity for any component to activate the entire unit increases with the strength of association among the components, and this unitization is increased whenever the components are associated (e.g., during correct production or study; Siegler, 1988) and then decreases with time due to spontaneous decay or interference. Thus, the strength with which the current problem activates previously retrieved nodes (and promotes positive error priming) depends on the residual unitization of those nodes due to previous retrievals. If such unitization is more likely to occur with true equations than false equations (i.e., because, in the latter case, the encoded relationship is ignored as irrelevant), we would expect stronger positive error priming from true than from false equations.

The results for positive error priming also bear on a tangential point. Campbell (1991) suggested that positive error priming could be related to the generation ef$f e c t$, in which recall or recognition probability is greater when items to be remembered are generated as opposed to only named. This was based on the observation that positive error priming occurred with previously retrieved answers but not with answers that had been named only. Crutcher and Healy (1989), however, obtained equivalent generation effects from multiplication production and verification tasks. Thus, the task-specific error priming observed in the present study casts doubt on the possibility that positive error priming and generation effects are manifestations of a common process.

The task specificity of positive error priming complements previous research demonstrating that the effect depends on the degree to which the error trial recapitulates the match trial in terms of processes of encoding and retrieval. Apart from Campbell's (1991) finding that retrieved but not named answers produce strong positive error priming, Campbell (1994) alternated format of presentation between Arabic digits (e.g., $4 \times 8=$ ?) and English number words (e.g., three $\times$ two $=$ ?) across trials. For both addition and multiplication, positive error priming was strong between same-format trials only, and was very weak between different presentation formats. Similarly, Arbuthnott and Campbell (in press) found that positive error priming was stronger when the error and match trial involved problems with a common operand presented in the same position (i.e., on the left or on the right). The hyperspecificity of positive error priming converges with much research showing that implicit priming often depends upon the similarity of encoding and testing conditions (see Masson \& Graf, 1993).

\section{Negative Error Priming}

In contrast to the task specificity of positive error priming, negative error priming occurred between verification trials and production errors. Specifically, produc- tion errors that involved either the correct or presented answer from the preceding verification trial were reduced. This concurs with other research on inhibitory processes demonstrating that multiple items can be inhibited simultaneously (Neumann \& De Schepper, 1992) and that inhibition can be directed to a variety of taskrelevant dimensions of stimuli (Tipper, Weaver, \& Houghton, in press). The dissociation between positive and negative error priming also concurs with previous error priming research showing that, whereas positive error priming depends on task-specific encoding and retrieval factors, negative error priming is insensitive to variations in encoding and task. For example, Campbell (1991) alternated multiplication-production trials with productnaming trials and found only weak positive priming of multiplication errors from previous naming trials, but strong negative priming (i.e., multiplication errors had a low probability of matching a just-named product). Similarly, whereas Campbell (1994) found little evidence of positive error priming between Arabic and wordbased stimuli, negative error priming was strong between problems presented in the different formats. Arbuthnott and Campbell (in press) found that positive error priming in simple addition was stronger between problems that shared a common operand in the same position (e.g., the error $4+8=11$ is more strongly primed by $4+7=$ ? than by $7+4=$ ? or $5+6=$ ?), but negative error priming was insensitive to whether successive problems shared a common operand.

Thus, like negative priming in selective attention (Tipper, 1985) and inhibitory effects in language comprehension (Gernsbacher \& Faust, 1991), negative error priming persists across variations in encoding and response conditions. Negative error priming in the production task is observed in association with immediately preceding answers regardless of whether the answer is named, retrieved, or only presented. As the effect is observed whenever an answer is processed, the effect is probably due to inhibition in answer retrieval or in responseproduction processes (Campbell \& Arbuthnott, in press). In the present experiment, when participants generated an answer on a production trial, they avoided the correct or presented answer to the previous verification trial. We do not know whether this effect is due to automatic or strategic processes, but Arbuthnott and Campbell (in press) demonstrated that negative error priming is robust even when there is a high probability that successive problems require the same response. Because inhibition of the preceding answer is nonadaptive when immediate repetition is frequent, this finding suggests that negative error priming is a spontaneous or automatic process rather than an intentional, strategic process. This possibility is consistent with MacKay's (1987) proposal that, once activated, verbal production processes may be spontaneously inhibited to reduce interference with subsequent production operations. Finally, there was no evidence of negative error priming of verification errors, which is consistent with the view that negative error priming reflects reduced accessibility of answer retrieval or 
production processes, and that verification in the present experiment did not generally involve these processes.

\section{Arithmetic Verification and the "Resonance" Theory}

The error priming results challenge Ashcraft's (1982, 1987) retrieve-compare model of verification. If the same answer retrieval process mediates both arithmetic verification and production, as the retrieve-compare model assumes, we would expect equivalent positive error priming within and between the production and verification tasks. In contrast, whereas previous production trials produced strong positive priming of production errors, production errors were only weakly primed by previous verification equations. Conversely, verification errors were primed by previous verification trials but not by previous production trials.

Zbrodoff and Logan's (1990) resonance model provides a straightforward explanation for this task-specific error priming. In this model, it is assumed that production and verification stimuli activate a common associative network structure, but that the two tasks are mediated by different memory macroprocesses. For the production task, one type of macroprocess analyzes the relative activation of individual memory nodes in the network in order to identify the most strongly activated node, which usually corresponds to the correct answer. For verification, a different macroprocess evaluates the total activation or resonance within the network, which provides an index of the familiarity or novelty of the problem-answer pair. Thus production and verification are proposed to differ both with respect to the type of retrieval mechanism engaged and the type of associative information evaluated. Given these assumptions, task-specific error priming may be explained if we additionally assume that each production or verification trial leaves a trace that corresponds to the specific associative information processed (i.e., specific answers or global familiarity). Subsequent processing interacts with this trace with the strength of the interaction increasing with the degree of overlap between the current and residual activation. Because the type of processing activated is task specific, production trials will interact most strongly with residual activation of production traces, whereas subsequent verification trials will interact with residual activation of verification traces.

The resonance model also explains the RT and accuracy differences among equations with true, related, and unrelated answers (see Table 1). According to Zbrodoff and Logan (1990), the verification decision is based on the total activation or resonance produced by the equation. If resonance quickly exceeds a minimum criterion, then the subject responds "true"; otherwise, the subject responds "false." A fast "false" response will be possible when resonance is perceived to not be building quickly, and a slow "false" response will occur when resonance builds at an intermediate rate without the threshold being reached. Given these assumptions, equations producing either very high or very low levels of resonance will produce high accuracy and fast RTs, whereas equations producing intermediate levels of resonance will yield longer RTs and lower accuracy. True equations usually would produce more resonance than false equations because they completely match a problem-answer relation in memory. Thus, we would generally expect faster RTs and fewer errors for true equations than for false equations. Nonetheless, unrelated false equations (e.g., $9 \times 3=32$ ) will be relatively easy because they do not match features of problem-answer pairs in memory and therefore produce weak resonance that is easy to distinguish from the strong resonance produced by true equations. Related false equations (e.g., $9 \times 3=18$ ), however, partially match at least one problem-answer association in memory (e.g., $6 \times$ $3=18$ ), and therefore generate an intermediate level of resonance that is difficult to distinguish from that produced by true equations.

Campbell (1987) found that differences in difficulty across multiplication problems observed in the production task were attenuated in verification. The verification group similarly demonstrated a smaller problem size effect for verification relative to simple production. In contrast, Ashcraft et al. (1984) found a comparable problem size effect for the two tasks using simple addition problems. This discrepancy might reflect differences in the processes underlying multiplication and addition (e.g., addition may involve more use of nonretrieval strategies, especially for larger problems; LeFevre et al., in press; Thibodeau, 1994). Another possibility suggested by the resonance model is that the magnitude of difficulty effects in verification will depend on the difficulty of discriminating true and false equations. In terms of the resonance model, the problem size or difficulty effect occurs because easy problems are based on strong problem-answer associations and quickly generate strong resonance, whereas the weaker associations underlying difficult problems build up resonance more slowly. Although retrieval difficulty in the production task also depends on associative strength, the difficulty effect may be attenuated in verification because discriminating the resonance produced by true and false equations can mask effects due to associative strength. For example, in the present study, the mean RT for "easy" related false equations ( $978 \mathrm{msec}$ ) was actually longer than that for both "difficult" unrelated false equations $(962 \mathrm{msec})$ and "difficult" true equations $(946 \mathrm{msec})$. Thus, the magnitude of the problem difficulty effect in verification will depend on the relative difficulty of the specific true-false discriminations for easy and difficult problems. If the true-false discriminations are either very easy or very difficult for both easy and difficult problems, then effects of differences in problem difficulty will be attenuated.

Taken together, the evidence of task-specific intertrial error priming, the specific effects of different types of presented answers on verification performance, and the attenuated problem difficulty effect in verification rela- 
tive to production support the conclusion that verification performance is based on judgments of familiarity or novelty, rather than on the answer retrieval process underlying simple production. Thus, the results are generally consistent with Zbrodoff and Logan's (1990) resonance model of verification and appear to challenge the retrieve-compare model.

\section{Primed Arithmetic Production}

With respect to the effects of true and false primes in the primed-production task, Meagher and Campbell (1995; see also Campbell, 1991) outlined two types of processes that might be involved, one based on familiarity or resonance, and another based on retrieval-priming processes. With familiarity-based processing, effects of numerical primes in the production task may arise from a prime verification strategy in which subjects assess the familiarity of the prime-problem combination and state the prime when familiarity is high. True (i.e., correct-answer) primes may produce strong familiarity, allowing subjects to state confidently the prime without necessarily retrieving the correct answer. With false primes, however, it is always necessary to retrieve an answer in order to produce a correct response; nonetheless, the familiarity produced by related prime-problem combinations may slow RTs and cause subjects to erroneously state the prime, producing prime intrusion errors.

Meagher and Campbell (1995) tested the prime verification hypothesis by eliminating correct-answer primes, which should eliminate a prime verification strategy because the prime is never the correct answer (see La Heij, Starreveld, \& Steehouwer, 1993; Roediger, Neely, \& Blaxton, 1983). With correct primes removed, interference effects of false primes were reduced. Nonetheless, Meagher and Campbell still observed significant interference effects (slowed RTs and increased errors) with related primes relative to unrelated and neutral (nonnumerical) prime conditions. These residual effects imply that a retrieval-priming process contributes to priming effects in arithmetic production. For example, a correct prime may directly activate the correct problem-answer relation in memory, facilitating retrieval of the correct answer. In contrast, false primes may activate competing associations that increase errors and slow answer retrieval (Wheeldon \& Monsell, 1994; see also Campbell, in press; Campbell \& Oliphant, 1992, for a detailed model of retrieval interference in simple arithmetic). Such interference would tend to be greater for related primes because converging activation from the prime and problem would cause especially strong activation of an incorrect response. This would produce a high rate of prime-intrusion errors with related primes, as observed.

The results of Meagher and Campbell (1995) suggest that primed production can involve both familiaritybased and retrieval-based processes, although answer retrieval is always necessary for a correct answer on a falseprime trial. However, the role of familiarity-based processing in the present primed-production experiment might have been minimal. In this study, primed produc- tion was alternated with simple production, which, relative to the Meagher and Campbell study, doubled the proportion of trials on which no numerical primes appeared. Consequently, subjects in the present primed-production study may have generally adopted a retrieval-based strategy. Indeed, differences between verification and primed production in the pattern of facilitation and interference effects (Table 1) may be explained in terms of different effects of the presented answers on familiarity-based (verification task) and retrieval-based (primed-production task) processes. In the context of primed production, true primes reduced errors by $68 \%$ and RTs by $75 \mathrm{msec}$ relative to the simple-production condition and, relative to the unrelated prime condition, true primes reduced errors by $79 \%$ and RTs by $165 \mathrm{msec}$. The strong facilitation due to correct-answer primes is expected with retrievalbased performance because the prime preactivates the correct problem-answer association. Conversely, false primes will tend to interfere with correct-answer retrieval, reducing performance relative to both correctprime and no-prime trials (Meagher \& Campbell, 1995). With familiarity-based verification, however, performance would largely be limited by the difficulty of distinguishing true $(4 \times 8=32)$ from related false equations $(4 \times 8=24)$, which both produce relatively strong familiarity. Thus, presentation of the correct answer in true verification did not produce strong facilitation relative to either simple-production or unrelated false equations $(4 \times 8=27)$.

\section{Retrieve-Compare Model of Verification Revisited}

Given evidence that familiarity decisions can be faster than answer retrieval (Reder \& Ritter, 1992), our conclusion that verification was mediated primarily by a familiarity strategy might appear to be contradicted by the finding that simple-production by the verification group was faster than their verification performance (Table 1). In contrast, the retrieve-compare model predicts longer RTs for verification than for production, as observed, because it assumes that verification involves an additional comparison stage not required for production. There are reasons to doubt that the longer RTs for verification than for production should be taken as support for the retrieve-compare model. First, processing of the verification equations required encoding of the presented answer, which would contribute to longer RTs relative to simple-production trials. Furthermore, familiarity and retrieval-based strategies may well involve different speed-accuracy functions, making absolute differences in speed or accuracy difficult to interpret. Finally, given that true primes substantially facilitated answer retrieval in the primed-production task, we might expect a similar facilitation effect in true verification if an answer retrieval stage generally mediated verification. Thus the longer RTs for true verification relative to simple production could be regarded as evidence against the retrieve-compare model.

Although we believe the evidence favors a familiaritybased account of the present verification data, it is im- 
portant to emphasize that the relative contribution of familiarity-based or plausibility-based strategies (see, e.g., Lemaire \& Fayol, 1995), as opposed to retrievalbased strategies, probably depends on a variety of factors. Familiarity- or plausibility-based performance is probably promoted when false answers are relatively easy to distinguish from true answers, whereas a retrievecompare strategy will be more probable when true and false answers are difficult to discriminate. A retrieveand-compare strategy also would be promoted when heavy emphasis is placed on accuracy, whereas an emphasis on speed would promote a familiarity strategy, given that reliable familiarity information will often be available more quickly than a specific answer. Indeed, our verification RTs $(M \approx 945)$ were somewhat faster than those observed by Koshmider and Ashcraft (1991, Experiment 1) for college students' multiplication verification $(M \approx 1,084)$, and these relatively fast response times might have promoted a familiarity-based strategy in our experiment. Furthermore, individuals who do not have well-developed memory for the arithmetic facts presumably rely on familiarity or plausibility under most conditions because they generally have low confidence in the accuracy of retrieved answers. Thus, although we conclude that verification performance in the present data was primarily mediated by familiarity, a retrievecompare strategy is possible and might be promoted by various conditions.

Nonetheless, the present findings support the conclusion that memory processes may be substantially different in the arithmetic production and verification tasks. Thus the results call into question applications of the verification task where it is assumed that arithmetic production and verification involve essentially identical computational processes. The present results, taken together with previous findings (Campbell, 1987; Dagenbach \& McCloskey, 1992; Krueger, 1986; Miller et al., 1984; Zbrodoff \& Logan, 1990), indicate that this assumption is not generally valid.

\section{REFERENCES}

Arbuthnot, K. D., \& Campbell, J. I .D. (in press). Effects of operand order and problem repetition on error priming in cognitive arithmetic. Canadian Journal of Experimental Psychology.

ASHCRAFT, M. H. (1982). The development of mental arithmetic: A chronometric approach. Developmental Review, 2, 213-236.

ASHCRAFT, M. H. (1987). Children's knowledge of simple arithmetic: A developmental model and simulation. In J. Bisanz, C. J. Brainerd, \& R. Kail (Eds.), Formal methods in developmental psychology (pp. 302-338). New York: Springer-Verlag.

AshCRAfT, M. H. (1992). Cognitive arithmetic: A review of theory and data. Cognition, 44, 75-106.

AshCRAFT, M. H., \& BatTAGLia, J. (1978). Cognitive arithmetic: Evidence for retrieval and decision processes in mental addition. Journal of Experimental Psychology: Human Learning \& Memory, 4, 527-538.

Ashcraft, M. H., Fierman, B. A., \& BartolotTa, R. (1984). The production and verification tasks in mental addition: An empirical comparison. Developmental Review, 4, 157-170.

Ashcraft, M. H., \& STAZYK, E. H. (1981). Mental addition: A test of three verification models. Memory \& Cognition, 9, 185-196.

Ashcraft, M. H., Yamashita, T. S., \& Aram, D. M. (1992). Mathe- matics performance in left and right brain-lesioned children and adolescents. Brain \& Cognition, 19, 208-252.

Campbell, J. I. D. (1987). Production, verification, and priming of multiplication facts. Memory \& Cognition, 15, 349-364.

CAMPBELL, J. I. D. (1991). Conditions of error priming in number-fact retrieval. Memory \& Cognition, 19, 197-209.

CAMPBeLL, J. I. D. (1994). Architectures for numerical cognition. Cognition, 53, 1-44

Camprell, J. I. D. (in press). Mechanisms of simple addition and multiplication: A modified network-interference theory and simulation. Mathematical Cognition.

CampBell, J. I .D., \& ARButhnotT, K. D. (in press). Inhibitory processes in sequential retrieval: Evidence from variable-lag repetition priming. Brain \& Cognition.

Campbell, J. I. D., \& Clark, J. M. (1989). Time course of errorpriming in number fact retrieval: Evidence for excitatory and inhibitory mechanisms. Journal of Experimental Psychology: Learning, Memory, \& Cognition, 15, 920-929.

Campbell, J. I. D., \& Oliphant, M. (1992). Representation and retrieval of arithmetic facts: A network-interference model and simulation. In J. I. D. Campbell (Ed.), The nature and origins of mathematical skills (pp. 331-364). Amsterdam: Elsevier, North-Holland.

Crutcher, R. J., \& Healy, A. F. (1989). Cognitive operations and the generation effect. Journal of Experimental Psychology: Learning, Memory, \& Cognition, 15, 669-675.

DAGENBACH, D., \& MCCloskey, M. (1992). The organization of arithmetic facts in memory: Evidence from a brain-damaged patient. Brain \& Cognition, 20, 345-366

FRENSCH, P. A., \& GEARY, D. C. (1993). Effects of practice on component processes in complex mental addition. Journal of Experimental Psychology: Learning, Memory, \& Cognition, 19, 433-456.

Gallistel, C. R., \& Gelman, R. (1992). Preverbal and verbal counting and computation. Cognition, 44, 43-74.

Geary, D. C., Widaman, K. F., \& LitTle, T. D. (1986). Cognitive addition and multiplication: Evidence for a single memory network. Memory \& Cognition, 14, 478-487.

Geary, D. C., Widaman, K. F., Little, T. D., \& Cormier, P. (1987). Cognitive addition: Comparison of learning disabled and academically normal elementary school children. Cognitive Development, 2 , 249-269.

Gernsbacher, M. A., \& Faust, M. E. (1991). The mechanism of suppression: A component of general comprehension skill. Journal of Experimental Psychology: Learning, Memory, \& Cognition, 17, 245 262.

Gillund, G., \& Shiffrin, R. M. (1984). A retrieval model for both recognition and recall. Psychological Review, 91, 1-67.

Gonzalez, E. G., \& Kolers, P. A. (1982). Mental manipulation of arithmetic symbols. Journal of Experimental Psychology, 8, 308319.

HAMANN, M. S., \& AshCRAFT, M. A. (1986). Textbook presentations of the basic addition facts. Cognition \& Instruction, 3, 173-192.

Humphreys, M. S., Bain, J. D., \& Pike, R. (1989). Different ways to cue a coherent memory system: A theory for episodic, semantic, and procedural tasks. Psychological Review, 96, 208-233

Koshmider, J. W., \& Ashcraft, M. H. (1991). The development of children's mental multiplication skills. Journal of Experimental Child Psychology, 51, 53-89.

KrUEGER, L. E. (1986). Why $2 \times 2=5$ looks so wrong: On the oddeven rule in product verification. Memory \& Cognition, 14, 141-149.

Krueger L. E., \& Hallford, E. W. (1984). Why $2+2=5$ looks so wrong: On the odd-even rule in sum verification. Memory \& Cognition, 12, 171-180.

La HeiJ, W., Starreveld, P. A.. Steehouwer, L. C. (1993). Semantic interference and orthographic facilitation in definition naming. Journal of Experimental Psychology: Learning, Memory, \& Cognition, 19, 352-368.

LeFevre, J., BisanZ, J., \& MrkonjIC, L. (1988). Cognitive arithmetic: Evidence for obligatory activation of arithmetic facts. Memory \& Cognition, 16, 45-53.

LeFEVre, J., SAdesky, G. S., \& Bisanz, J. (in press). Selection of procedures in mental addition: Reassessing the problem-size effect in 
adults. Journal of Experimental Psychology: Learning, Memory, \& Cognition.

Lemaire, P., Barrett, S. E., \& FAyOl, M. (1994). Automatic activation of addition and multiplication facts in elementary school children. Journal of Experimental Child Psychology, 57, 224-258.

Lemaire, P., \& FAYOL, M. (1995). When plausibility judgments supersede fact retrieval: The example of the odd-even effect on product verification. Memory \& Cognition, 23, 34-48.

MACKAY, D. G. (1987). The organization of perception and action: A theory for language and other cognitive skills. New York: Springer-Verlag.

Masson, M. E. J., \& GRAF, P. (1993). Introduction: Looking back into the future. In P. Graf \& M. E. J. Masson (Eds.), Implicit memory: New directions in cognition, development, and neuropsychology (pp. 1-11). Hillsdale, NJ: Erlbaum.

McCloskey, M., Sokol, S. M., \& Goodman, R. A. (1986). Cognitive processes in verbal-number production: Inferences from the performance of brain-damaged subjects. Journal of Experimental Psychology: General, 115, 307-330.

MEAGHER, P. D., \& CAMPBELL, J. I. D. (1995). Effects of prime type and delay on multiplication priming: Evidence for a dual-process model Quarterly Journal of Experimental Psychology, 48A, 801-821.

METCALFE, J. (1993). Novelty monitoring, metacognition, and control in a composite holographic associative recall model: Implications for Korsakoff amnesia. Psychological Review, 100, 3-22.

Miller, K., \& Perlmutter, M., \& Keating, D. (1984). Cognitive arithmetic: Comparison of operations. Journal of Experimental Psychology: Learning, Memory, \& Cognition, 10, 46-60.

NeumanN, E., \& De Schepper, B. G. (1992). An inhibition-based fan effect: Evidence for active suppression mechanisms in selective attention. Canadian Journal of Psychology, 46, 1-40.

NoËL, M.-P., \& SERON, X. (1992). Notational constraints and number processing: A reappraisal of the Gonzalez and Kolers (1982) study. Quarterly Journal of Experimental Psychology, 45A, 451-478.

REDER, L. (1987). Strategy selection in question answering. Cognitive Psychology, 19, 90-137.

RedER, L., \& RitTER, F. (1992). What determines initial feeling-ofknowing? Familiarity with question terms, not with the answer. Journal of Experimental Psychology: Learning, Memory, \& Cognition, 18, 435-451

Rickard, T., Healy, A. F., \& Bourne, L. (1994). On the representation of arithmetic facts: Operation, order, and symbol transfer effects. Journal of Experimental Psychology: Learning, Memory, \& Cognition, 20, 1139-1153.

Roediger, H. L., Neely, J. H., \& Blaxton, T. A. (1983). Inhibition from related primes in semantic memory retrieval: A reappraisal of Brown's (1979) paradigm. Journal of Experimental Psychology. Learning, Memory, \& Cognition, 9, 478-485.

Rogers, W. A., \& FISK, A. D. (1991). Age-related differences in the maintenance and modification of automatic processes: Arithmetic Stroop interference. Human Factors, 33, 45-56.

SIEGLER, R. S. (1988). Strategy choice procedures and the development of multiplication skill. Journal of Experimental Psychology: General, 117, 258-275.

STAZYK, E. H., \& Ashcraft, M. H., \& HamanN, M. S. (1982). A network approach to mental multiplication. Journal of Experimental Psychology: Learning, Memory, \& Cognition, 8, 320-335.

Thibodeau, M. (1994, June). Adults' strategies for simple addition and multiplication. Paper presented at the annual meeting of the Canadian Society for Brain, Behaviour, and Cognitive Sciences, Vancouver.

TIPPER, S. P. (1985). The negative priming effect: Inhibitory priming of ignored objects. Quarterly Journal of Experimental Psychology, 37A, 571-590.

Tipper, S. P., Weaver, B., \& Houghton, G. (in press). Behavioral goals determine inhibitory mechanisms of selective attention. Quarterly Journal of Experimental Psychology.
WHEELdon, L. R., \& MonselL, S. (1994). Inhibition of spoken word production by priming a semantic competitor. Journal of Memory \& Language, 33, 332-356.

Widaman, K. F., \& LitTle, T. D. (1992). The development of skill in mental arithmetic: An individual differences perspective. In J. I. D. Campbell (Ed.), The nature and origins of mathematical skills (pp. 189-253). Amsterdam: Elsevier, North-Holland.

Winkelman, J., \& SchmidT, J. (1974). Associative confusions in mental arithmetic. Journal of Experimental Psychology, 102, 734-736.

ZBRodofF, N. J., \& LOGAN, G. D. (1986). On the autonomy of mental processes: A case study of arithmetic. Journal of Experimental Psychology: General, 115, 118-130.

ZBRODOFF, N. J., \& LOGAN, G. D. (1990). On the relation between production and verification tasks in the psychology of simple arithmetic. Journal of Experimental Psychology: Learning, Memory, \& Cognition, 16, 83-97.

\section{NOTES}

1. A retrieve-compare strategy for arithmetic verification may be expected only when false equations are plausible (Ashcraft \& Stazyk, 1981). If the split is very large, for example, subjects can quickly recognize that an equation is implausible, obviating answer retrieval. For the present experiment, the average split was 9.2 , and in $74 \%$ of cases the split was $\leq 10$. The average percentage of deviation from the correct product was $41 \%$, which is within the range where split has minimal effects on multiplication. Stazyk, Ashcraft, and Hamann (1982, Experiment 2) found substantial split effects for multiplication only when splits were $65 \%$ of the correct product or greater. Furthermore, when split is expressed in terms of operand units (i.e., split/the larger multiplier), the average split in the present experiment was 1.5 , which is close to the average distance of errors generated in the production task (i.e., most multiplication production errors correspond to the correct answer obtained if one of the operands is changed by \pm 1 or \pm 2 ; Campbell, 1994). Thus, in general, false answers were plausible and it is unlikely that splits were large enough to obviate retrieval, even if subjects were likely to use a retrieve-compare strategy for verification.

2. Several previous primed-production experiments have shown a small RT cost ( $\approx 15-30 \mathrm{msec}$ ) with related primes relative to unrelated primes (Campbell, 1987, 1991; Meagher \& Campbell, 1995). This effect was not observed in the priming data. The failure to observe the RT difference between related and unrelated primed-production conditions in the present experiment is probably due to the emphasis on speed. RTs in the present primed-production experiment were about $100 \mathrm{msec}$ faster than those found in Campbell (1991) and the overall error rate was more than double that observed by Campbell. Furthermore, the difference in error rate between related primes and unrelated primes was about twice that observed by Campbell $(+9.9 \%$ vs. $+4.3 \%)$. It appears that subjects adopted a response deadline that masked differential RT costs of related relative to unrelated primes, but that exaggerated the effects of related primes on errors

3. The problem size or difficulty effect can also be analyzed in terms of structural variables such as the problem's correct product (Ashcraft, 1992; Widaman \& Little, 1992). To confirm the greater difficulty effect for production relative to verification in the verification data, we calculated the mean RT for correct trials for each problem and regressed problem RT (in milliseconds) on the correct product $(P)$. We followed the common convention of excluding tie problems from the analysis. The regression equation was $\mathrm{RT}=774+P 4.53(r=.71)$ for the production task, $846+P 2.55(r=.77)$ for true verification, $958+$ $P 2.24(r=.79)$ for related false verification, and $880+P 2.24(r=.83)$ for unrelated false verification. Thus, the slope of the difficulty effect for RT in the production task was approximately two times the slope observed for both true and false verification. 
APPENDIX

Related and Unrelated False Answers Assigned to Each Problem for the Verification and Primed Production Tasks

\begin{tabular}{|c|c|c|c|}
\hline Problem & Correct & Related & Unrelated \\
\hline \multicolumn{4}{|c|}{ "Easy" Problem Set } \\
\hline $2 \times 2$ & 4 & 8 & 9 \\
\hline $2 \times 3$ & 6 & 12 & 13 \\
\hline $2 \times 4$ & 8 & 16 & 15 \\
\hline $2 \times 5$ & 10 & 25 & 21 \\
\hline $2 \times 6$ & 12 & 16 & 15 \\
\hline $2 \times 7$ & 14 & 21 & 25 \\
\hline $2 \times 9$ & 18 & 27 & 25 \\
\hline $3 \times 3$ & 9 & 6 & 8 \\
\hline $3 \times 4$ & 12 & 24 & 30 \\
\hline $3 \times 5$ & 15 & 25 & 28 \\
\hline $3 \times 7$ & 21 & 27 & 25 \\
\hline $4 \times 4$ & 16 & 8 & 6 \\
\hline $4 \times 5$ & 20 & 15 & 14 \\
\hline $5 \times 5$ & 25 & 20 & 21 \\
\hline $5 \times 6$ & 30 & 35 & 32 \\
\hline $6 \times 6$ & 36 & 12 & 16 \\
\hline $7 \times 7$ & 49 & 42 & 45 \\
\hline $9 \times 9$ & 81 & 54 & 49 \\
\hline \multicolumn{4}{|c|}{ "Difficult" Problem Set } \\
\hline $2 \times 8$ & 16 & 18 & 15 \\
\hline $3 \times 6$ & 18 & 24 & 35 \\
\hline $3 \times 8$ & 24 & 18 & 14 \\
\hline $3 \times 9$ & 27 & 18 & 32 \\
\hline $4 \times 6$ & 24 & 28 & 25 \\
\hline $4 \times 7$ & 28 & 21 & 27 \\
\hline $4 \times 8$ & 32 & 24 & 27 \\
\hline $4 \times 9$ & 36 & 45 & 42 \\
\hline $5 \times 7$ & 35 & 45 & 27 \\
\hline $5 \times 8$ & 40 & 45 & 42 \\
\hline $5 \times 9$ & 45 & 40 & 49 \\
\hline $6 \times 7$ & 42 & 63 & 64 \\
\hline $6 \times 8$ & 48 & 72 & 63 \\
\hline $6 \times 9$ & 54 & 63 & 64 \\
\hline $7 \times 8$ & 56 & 42 & 36 \\
\hline $7 \times 9$ & 63 & 56 & 48 \\
\hline $8 \times 8$ & 64 & 72 & 54 \\
\hline $8 \times 9$ & 72 & 63 & 49 \\
\hline
\end{tabular}

Note-Correct, correct answer; Related, related false answer; Unrelated, unrelated false answer. The division into "easy" and "difficult" problems is based on the normative response time data reported by Campbell and Graham (1985).

(Manuscript received September 19, 1994; revision accepted for publication April 13, 1995.) 